International Journal of Engineering \& Technology, $7(2.6)(2018) 168-170$
International Journal of Engineering \& Technology
SPC
Website: www.sciencepubco.com/index.php/IJET
Research Paper

\title{
Design of a High Gain Compact Circular Microstrip Patch Antenna for X-Band
}

\author{
Madhukant Patel $^{1 *}$,Veerendra Singh Jadaun ${ }^{2}$, Kanhiya Lal ${ }^{2}$, Piyush Kuchhal ${ }^{3}$ \\ ${ }^{1}$ PhD Scholar, University of Petroleum and Energy Studies, Dehradun, India. \\ Former Scientist/ Engineer ISRO, Reve Automation, Gandhinagar,Gujrat, \\ ${ }^{2}$ Sr. Microwave Engineer, Sahajanand Laser Technology Ltd., Gandhinagar, Gujrat, \\ 3 Professor, University of Petroleum and Energy Studies, Dehradun, India. \\ *Corresponding Author Email: madhukant.patel@ reveautomation.com
}

\begin{abstract}
This paper presents design a High Gain Small Size Microstrip Patch Antenna for X-Band applications such as Moving target RADAR sensor, Motion detector, Microwave camera, Ground Penetration RADAR sensors, wall penetration scanners and many medical applications. Now we have to selected circular geometry of micro strip patch antenna because circular geometry overcomes edge effect of antenna. The proposed antenna is designed to operate for X-band at the centre frequency of $10 \mathrm{GHz}$. The proposed Circular patch antenna is compact and easy to body mount with a high efficiency. The compactness makes it a better choice as compare with other antenna in the X-band. The proposed antenna shows a very sharp return loss of $-46 \mathrm{~dB}$ at $10 \mathrm{GHz}$ having narrow pattern with a good gain of $4.7 \mathrm{dBi}$ This enables its use in high directional applications. The paper represents the designing steps, and the simulation result obtained. The software used here for this circular shaped microstrip antenna is IE3D. Various parameters such as gain, power, radiation pattern, and $\mathrm{S}_{11}$ of the antenna are mentioned.
\end{abstract}

Keywords: Circular Microstrip Antenna, X-band, Gain, Return loss, Bandwidth.

\section{Introduction}

Antenna is a transducer which convert electrical signal into Electromagnetic Signal .Microstrip antennas are compact and high power handling, low cost and easily surface mounted one. These antennas are easily integrated with printed feed networks consisting of strip lines on any active devices [1]. This property of microstrip antenna gains new area of antenna engineering.

Mircrostrip antenna technology has others advantages such as light weight and low cost in fabrication. These can operate in narrow band and wide band over the entire spectrum of SHF, thus makes it a good choice in widely adopted antenna design. Microstrip antennas have many applications in the field related to military, personal, medical, mobile and satellite communications. The have gained a good utilization because of size and weight. This with cost effective fabrication and prototyping is very important in the performance evaluation. As most of the versatile communications found their place in X-band, hence the demand of suitable andeffective microstrip antennas at X-band of operation becomes very much in demand[2]. Microstrip antenna shows narrow bandwidth, and their performance is dependent on the properties of substrate.

In its most simplest and basic form, a Microstrip antenna is consisting of a radiating patch and a conducting ground plane. These two are separated by a dielectric material. The patch is also made of conducting material and its shape can take any possible structure. This radiating patch is carved out or photo etched on the surface of substrate. For the simplification of design and analysis, the shape of the patch is either of rectangular, square, rectangular, circular, elliptical and triangular or any of common shape. The circular shape is chosen for our study and described in this paper [3].

The proposed antenna of the diameter $8 \mathrm{~mm}$ with circular patch is designed over FR4 epoxy with centre frequency of $10 \mathrm{GHz}$. The thickness of this antenna is $1.6 \mathrm{~mm}$. FR4 as dielectric substrate of appropriate thickness is chosen because of easy commercial availability of $1.6 \mathrm{~mm}$ thick substrate for the designing of the proposed circular microstrip antenna. A thicker substrate provides a mechanically strong structure and also it improves the impedance bandwidth [4]. Gain of the antenna is also in line with the thickness of the substrate. The permittivity of the dielectric substrate also plays an important role as that of thickness of it. FR4 epoxy substrate is a grade designation that is allocated to glass reinforced epoxy laminate sheets or printed circuit boards. This also finds its easiness in the integration with the circuit board for the microstrip antenna. FR4 is also good with strength to weight ratios, and is commonly used as an electrical insulator having good mechanical strength [5].

This paper presents a printed circular microstrip antenna exclusively for high gain in $\mathrm{X}$ band application. A typical and simple schematic diagram of circular microstrip antenna is shown in figure 1. 


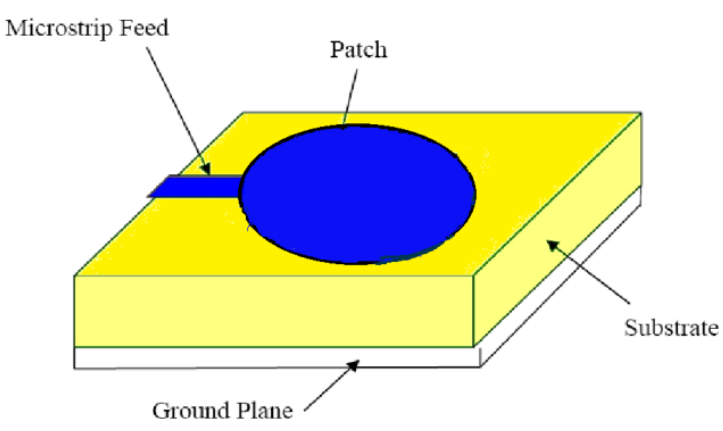

Fig:1 Microstrip Circular patch antenna

The design and simulation of $\mathrm{X}$ - band operating circular microstrip antenna is done using IE3D software. It is EM solver working on the principle of Method of Moments.

\section{Design and analysis antenna}

First step for designing of any microstrip patch antenna is the selection of a resonance frequency [6]. Next selection is that of substrate material property like permittivity and loss tangent of material with substrate thickness. In this proposed paper $10 \mathrm{GHz}$ is resonance frequency of antenna and circularpatch is carved on FR4 (Glass Epoxy) dielectric material of dielectric constant (cr) 4.4. itsdielectric loss tangent is 0.02 and the height of the substrate is $1.6 \mathrm{~mm}$.The parameters for the design of a circular microstrip patch antenna are operating frequency (f), radius of the patch (a), dielectric constant of the substrate (cr), and height of the substrate (h). The overall size of the antenna is dependent on these parameters. The central frequency selected for design is $10.0 \mathrm{GHz}$. The material for dielectric substrate for the proposed design is FR4 epoxy of dielectric constant of 4.4 and loss tangent of 0.027 . The height of the substrate is chosen high for adding the volume to compact and small design. Also it is important that the antenna is not bulky, so the height is chosen to be $1.6 \mathrm{~mm}$.

After rectangular patch, circular patch shape is next configuration with ease. Also it has many applications as a single patch element. A circular microstrip antenna, whose substrateheight is small (h $<<\lambda$ ), supports TMz modes, where $\mathrm{z}$ is perpendicular to the radiating patch[7]. The circular patch of the microstrip antenna has only one degree of freedom to control, and it is its radius. The radius of the patch does not affect the order of the modes but it is directly related to the central resonant frequency. This one degree of freedom, the radius of the patch, makes the designing of circular shaped microstrip antenna easier than other geometrical patch shaped configuration.

Antenna geometry dimensions are calculated by using transmission line model equations [8]. Inset feeding used as a feeding method.

The principle formulas used for calculating radius(a) is

$$
\mathrm{a}=\mathrm{F}\left[1+\frac{2 \mathrm{~h}}{\pi \mathrm{F} \varepsilon_{\mathrm{r}}}\left\{\ln \left(\frac{\pi \mathrm{F}}{2 \mathrm{~h}}\right)+1.7726\right\}\right]^{-1 / 2}
$$

where, $\quad F=\frac{8.791 \times 10^{9}}{\mathrm{f}_{\mathrm{r}} \sqrt{\varepsilon_{\mathrm{r}}}}$

In the above equations, the operating frequency (f) is in Hertz $(\mathrm{Hz})$ and the height of thesubstrate $(\mathrm{h})$ is in millimeters $(\mathrm{mm})$.

Table 1: Design Parameter of X- Band Microstrip circular shaped Antenna

\begin{tabular}{ll}
\hline Radius (a) & $4 \mathrm{~mm}$ \\
\hline Input Impedance of Patch & $50 \Omega$ \\
Width of microstrip line & $0.2 \mathrm{~mm}$ \\
Length of microstrip line & $1.5 \mathrm{~mm}$ \\
\hline
\end{tabular}

In microstrip line feeding technique, an antenna is connected to the source by a characteristic impedance transmission line $\mathrm{Zc}$ of $50 \mathrm{Ohm}$. This is done to ensure maximum transfer of power from the source to radiating patch of antenna. Hence it is very much required to ensure an impedance matching. This matching allows in reducing the reflection coefficient at the input of the antenna. The reflection coefficient parameter is dependent on the dimension of the antenna and its characteristic impedance. The calculation of the characteristic impedance of matching feed line is calculated the formula as below.

$$
\mathrm{Zc}=(\mathrm{Z} 50 \times \mathrm{Zpatch}) 1 / 2
$$

For the simulation and analysis process IE3D simulator is used with the antenna design parameters. The various resultant parameters such as return loss, gain etc are analysed. Figure 2 is the IE3D simulator diagram of the antenna.

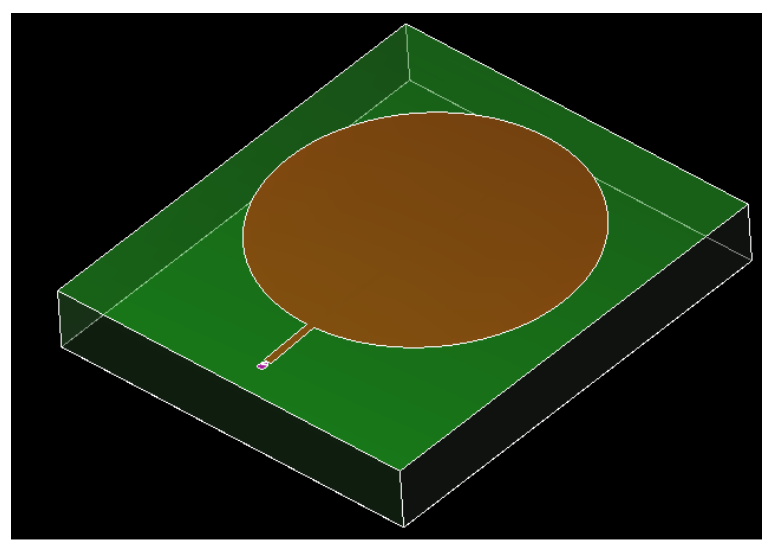

Fig.2: Circular Microstrip patch antenna

Return Loss and bandwidth- The observation is recorded from 9 $\mathrm{GHz}$ to $11 \mathrm{GHz}$, as this range is the middle of X-band. The antenna shows resonance from $9.5 \mathrm{GHz}$ onwards. Its response is slow and linear upto this frequency right from $9 \mathrm{GHz}$. This antenna has achieved a high value of the order of $-46.24 \mathrm{~dB}$ of return loss at 10 GHzresonant frequency as shown in figure 2. Its obtained bandwidth, on the scale of $-10 \mathrm{~dB}$, is found to be $50 \mathrm{MHz}$ which is shown in figure 3 . At this resonant frequency antenna radiate maximum power. As observed in the figure the radiation nature of the antenna is sharp around $10 \mathrm{GHz}$ of frequency.

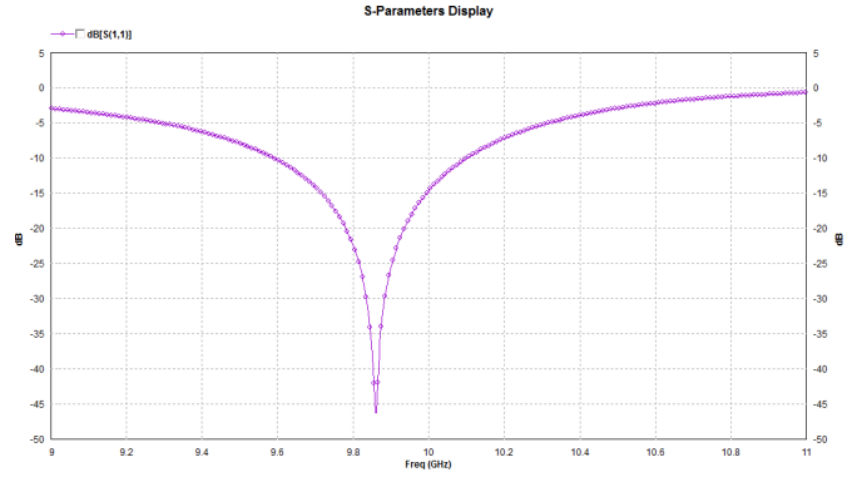

Fig.3: variation between return loss and frequency

VSWR- voltage standing wave ratio (VSWR) of antenna is parameter of impedance matching of antenna. If antenna radiates all of its transmitted power within the operating range of frequency than VSWR will be 1:1. It is shown in the figure 4 circular patch antenna VSWR obtained as 1.009796:1. The pattern of VSWR resembles a sharp radiating nature. 


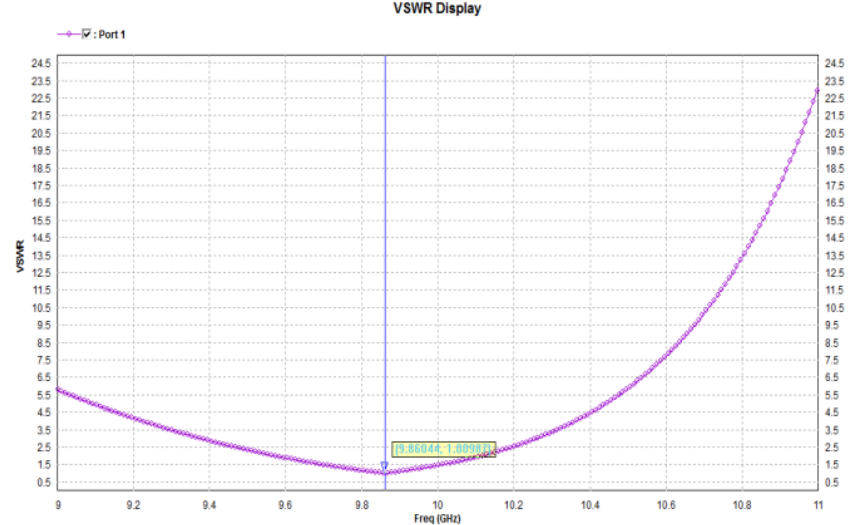

Fig.4: VSWR of circular microstrip patch antenna

Gain of Proposed Antenna- Gain is a very important parameter for any antenna, if the gain of antenna is high than maximum power radiated with high directivity. The maximum gain of the proposed antenna is obtained at $4.7 \mathrm{dBi}$ at the centre operating frequency of $10 \mathrm{GHz}$ as shown in figure 5 . This is very good for small geometry. The pattern of the gain over the frequency range is also uniform.

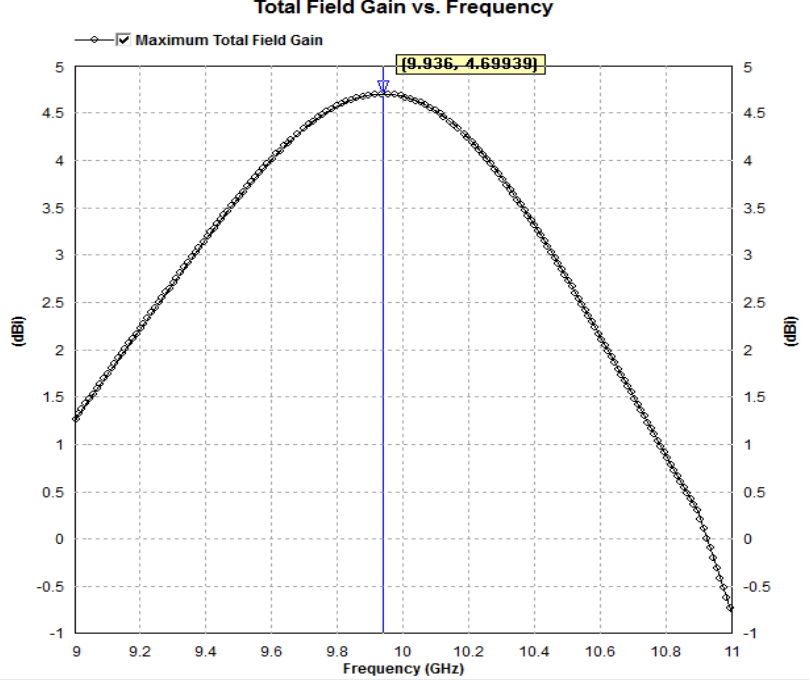

Fig.5: Gain of circular microstrip patch antenna

Antenna efficiency of Proposed Antenna-Antenna efficiency is another important parameter for any antenna. If the efficiency of an antenna is near to $100 \%$ than total input power is radiated without any dissipation loss, and it results in the maximum power radiated with high directivity. The proposed circular shaped antenna obtained an efficiencyof60\%. The efficiency is also uniform and maintained in excess of $50 \%$ at $\pm 200 \mathrm{MHz}$ of operating central frequency as shown in figure 6 . This is also very good for small geometry of the proposed antenna.

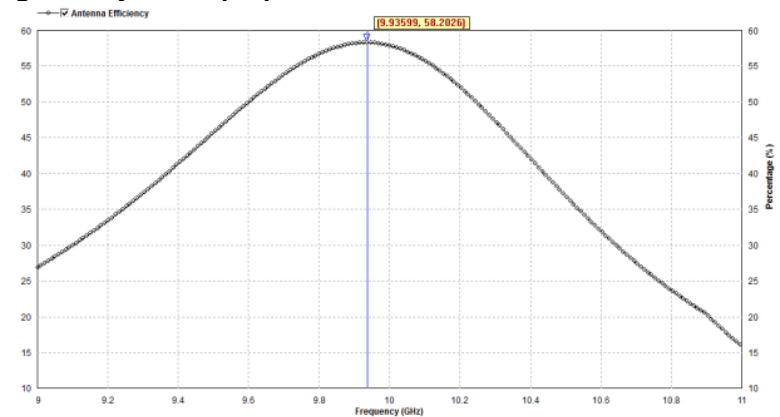

Fig.6: Antenna efficiency of Proposed Antenna

\section{Conclusion}

A parametric study based on the IE3D simulation of the circular shaped compact microstrip antenna is presented in the paper. The analysis of the various antenna parameter shows that characteristics of proposed antenna enhanced is well suited for X-Band applications especially application that includes radar communication and military communication with good acceptable gain. Band width and gain of proposed antenna is also acceptable. Fabrication on low cost material with compact dimension gives it an edge.

\section{References}

[1]. Ranjan Mishra, An Overview of Microstrip Antenna, HCTL Open International Journal of Technology Innovations and Research (IJTIR), Volume 21, Issue 2, August 2016

[2]. Raj Gaurav Mishra, Ranjan Mishra, Piyush Kuchhal and N. Prasanthi Kumari, "Optimization and analysis of high gain wideband microstrip patch antenna using genetic algorithm", International Journal of Engineering \& Technology, 7 (1.5) (2018) 176179.

[3]. T.F.Lai, Wan Nor Liza Mahadi, NorhayatiSoin, "Circular Patch Microstrip Array Antenna for Ku-band" World Academy of Science, Engineering and Technology 48, 2008.

[4]. R. Mishra, R. G. Mishra and P. Kuchhal, "Analytical study on the effect of dimension and position of slot for the designing of ultra wide band (UWB) microstrip antenna," IEEE International Conference on Advances in Computing, Communications and Informatics (ICACCI), 2016, pp. 488-493.

[5]. Analysis of Five Different Dielectric Substrates on Microstrip Patch Antenna in International Journal of Computer Applications (0975 - 8887) Volume 55- No.14, October 2012.

[6]. A.Al-Zoubi, F. Yang, and A. Kishk, "A broadband center-fed circular patch-ring antenna with amonopole like radiation pattern," IEEE Transaction Antennas Propagation, vol. 57, pp. 789$792,2009$.

[7]. C.A. Balanis, Antenna Theory, 2nd Ed., John wily \& sons, New York.1982.

[8]. R. Garg, P. Bhatia, I. Bahl and A. Ittipiboon, "Microstrip Antenna Design Handbook", Artech-House, 2001. 